\title{
Instigating Smart City Infrastructure in Oman: Considering Social Benefits and Economic Values
}

\author{
Waleed Mubarak Al-Yousfi \\ Hussin A.M Yahia \\ Ram Kishore
}

\begin{abstract}
Smart city is a group of technologies application used to improve the quality of people life by making services easier. The main requirements of smart city are both of physical infrastructure and technology infrastructure. Smart cities are including such as renewable energy, water quality, sewage management, transportation management, smart health, smart parking, waste management, electric vehicle charging, smart home, air pollution management, intelligent shopping, traffic management, smart environment, public safety, smart building, and internet of things. Through evaluating of main cities in Oman, it is time to develop the life style and living of people. This led to change of human life culture in dealing with a smart infrastructure. Smart city is concentered to connect the living city with some factors which improve high quality life and sustainable development services to citizens. The research will focus in analysis and identify the ability of converting capital cities like Muscat to smart city and trying to find common barriers of implement the smart city infrastructure. Also, it will evaluate economics and social effects of smart cities to the human life of Oman culture and develop the framework of smart city infrastructure in Oman. The methodology was used triangulation data method in this study which conducting the data received from three parts include data collection, quantitative method and qualitative method. Each analysis was done through different method to reach main results. The significant Findings discussed to cover the requirements of research objectives. Most of findings indicates that smart cities are popular from public because of its benefits in different sides. The results found that main cities in Oman can be converting to smart cities by developing the both physical and technology infrastructures. In addition, smart cities require a strategic plan to attract the global investment and improving the local business such as tourism and industrial areas. It is recommended that smart cities can improve public service and required to make facilities faster and cheaper.
\end{abstract}

\section{Introduction}

Infrastructure development is one of the most important factors that change human life. During the last few years, it has been observed that many countries are concerned about the principle of infrastructure development in urban cities. However, they found applying smart technologies in countries is the main area of growing economic. Smart cities have urban culture that can utilize the information technology (IT) and communication applications with some additional innovations in order to produce sustainable development services. Also, these cities have the environment to improve the life style of citizens to a high-quality living by implementing technologies.

In Oman, the population has increased rapidly around $8 \%$ annually in the last four years, as it has reached to 4.6 million as per NCSI and ROP registration in March 2019. It is expected that the population will further increase by around 2.4 million in 2040. In addition, the statistic shows that around $60 \%$ of the people in Oman are concentrated in the urban cities such as Muscat, Sohar, Sur, Nizwa, Salalah and others. Compared to others, Muscat has the highest number and is represented by around 30 \% from the total population. (About Oman 2019) Smart cities are 


\section{Journal of Student Research}

Fourth Middle East College Student Research Conference, Muscat, Sultanate of Oman

attractive and popular for most leading and developing countries by developing the technology. It is the way where the environment becomes more suitable and useful for the government and the public. Services become easier by using technology. Statistics shows that broadband connection will mostly cover $95 \%$ of rural areas through satellite or mobile broadband in the next few years. On the other hand, the mobile number subscribers have reached around 6.4 million.

The idea of smart cities is to use different types of electronic sensors to collect data and information, and manage the data to monitor citizen services. There are a lot of services which can be managed in a smart city such as transportation and traffic system, power system, water and wastewater network management, waste management, home and building, education and health management and other community services.

There are many examples of smart cities around the world. Most of the smart cities are successful for the government and useful to the citizens. It is becoming a tool for most countries to develop cities in many aspects like economy, tourism, industry, technical and others. Examples of cities where smart technologies have been implemented are: Barcelona, New York, Stockholm, Madrid, Amsterdam, Singapore, Dubai, Southampton, Milan and Shanghai.

The status of a smart city in Oman is still in planning and researching stage. It is observed that the government is planning to implement the smart city concept in some main cities in different governorates.

The aim of this research is to analysis the social benefits and economic values by implementing the smart city infrastructure in different areas in Oman.

\section{The main objectives are as follow:}

1. Analyze and identify the ability of converting main capital cities to smart cities and identify the barriers in implementing the smart city infrastructure in Oman,

2. Evaluate the economic and social effects of smart cities on human life, and on the Oman culture, and

3. Develop the framework of smart city infrastructure in Oman by selecting samples as case study.

The research will focus on the development of smart city infrastructure in Oman by researching the area which is suitable to implement technologies. However, before starting any implementation for smart city, the research will try to find how far cities in Oman are ready to be smart. The methodology of the paper will be based on research methods used in many studies which were done outside and inside Oman. It will give an idea to bring in new thinking to our country, Oman, that can help to make changes to the infrastructure such as transportation, buildings, technology system, waste management, pollution management, water management, electricity, CCTV and other services. Then, it will evaluate services for social benefits and how far they are useful to the community. The main area is evaluating the infrastructure in the country, then trying to add smart technologies which can lead to smart cities in some areas in Oman.

\section{Literature Review}

The smart city theory was initiated by two scientists named Graham and Pomeroy in the year of 1990s (Hongbo et al. 2018). Smart city has been presented to spot the advantages of information and communication technology (ICT) during the previous 20 years (UKEssays 2013). According to Keta (2015) explained the period were presented stages of smart city development which was during the beginning of 2000 then improved to be covered by social in 2005 and the community in 2005 where it became part and quality of life in 2010. Debra and John (2018) stated that first used of smart city in the 1990s, also the name become common between academics and scientists and 


\section{Journal of Student Research}

Fourth Middle East College Student Research Conference, Muscat, Sultanate of Oman

others. Most of studies were mentioned the beginning period of smart cities which is since around 20 years. But, in Los Anglos it seems that they used technology in the early of 1960s to interpret, gather and visualize civic data. However, los Anglos' make decisions about policy which is a sign that smart city idea is not modern urbanism trend (Architexturez 2015).

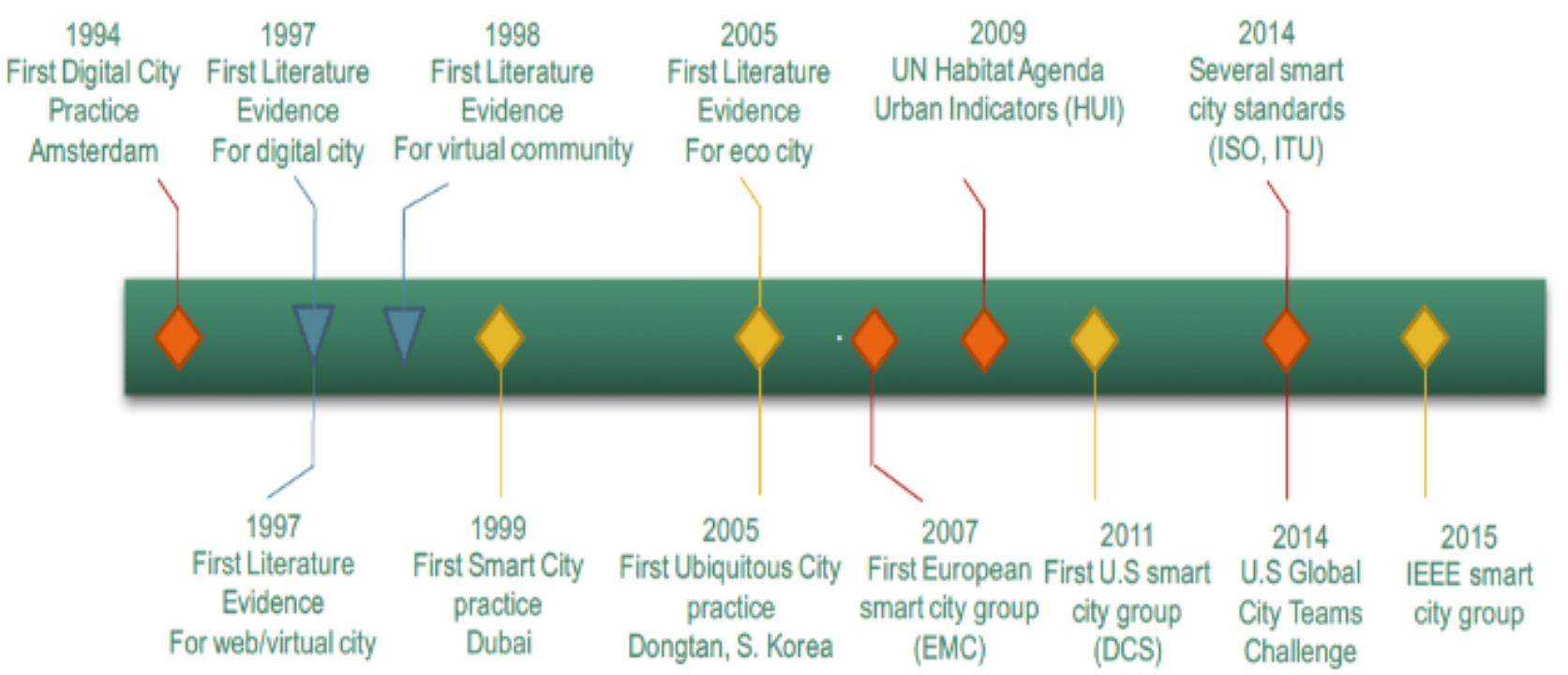

Figure 1. Timeline of Smart Cities

It is observed that there is no general definition for smart city but most of past literature and sources mentioned factors and results close from each other. In addition, some research mentioned the name of smart city in different way like development city, intelligent city, human city, knowledge city, learning city, hybrid city, information city, skilled city, digital city, creative city and other names (Alawdah 2017). Sik (2016), said smart city is the city which can provide better life than before. (Ignasi and Matías 2018) suggests that smart city is managing of ICT to enhance the citizens life while impacting the sustainable development of infrastructure. Smart city is a community that citizen, knowledge institutions, business firms and municipalities working and collaborating with each other to achieve the quality of life required (Sajid et al. 2017). Smart cities are function like a ladder by using technology and information in smart city foundation which give opportunities for creating city competitiveness by developing life quality of city populations (Ayşen 2018). Smart city is defined as an application of technology, data and techniques, supporting tools to advance the quality of life by three key area: function, vision and components (Debra and John 2018).

Jalali (2017) suggests that smart city is providing a good infrastructure for improving several applications and software which raise the quality of living for citizen and simplify facilities offered by the city. The smart city concept is integrating with different category of dimensions like institutional, physical and digital spaces to introduce aspects required such feedback, interconnection, adaptation and self-organization that to provide full understanding of operation and evaluation of cities (Radovan 2014). Technology of smart city is the main enable in achieving livable and sustainable city by support the overall development plan and strategy to establish excellent governance and identify most suitable technical to citizen (Ramboll 2019). According to Aaron Hesse (2017), identified in short that smart city used network devices and data analytics to active power from big data and IoT which can improve the quality of people lives in populated urban cities.

There are wide range of services provided in smarter way. These services can be used by government for business and management, and by citizens for improving life quality. These services 


\section{Journal of Student Research}

covered transportation, education, health care, public utilities and public safety. Transportation services provided by using of intelligent road networks which linked public transport and cars. Services included electricity, water, wastewater and gas which provided by smart network distribution and smart metering. Also, smart cities concept is focusing in smart building and homes which is the main role of adapting with services development.

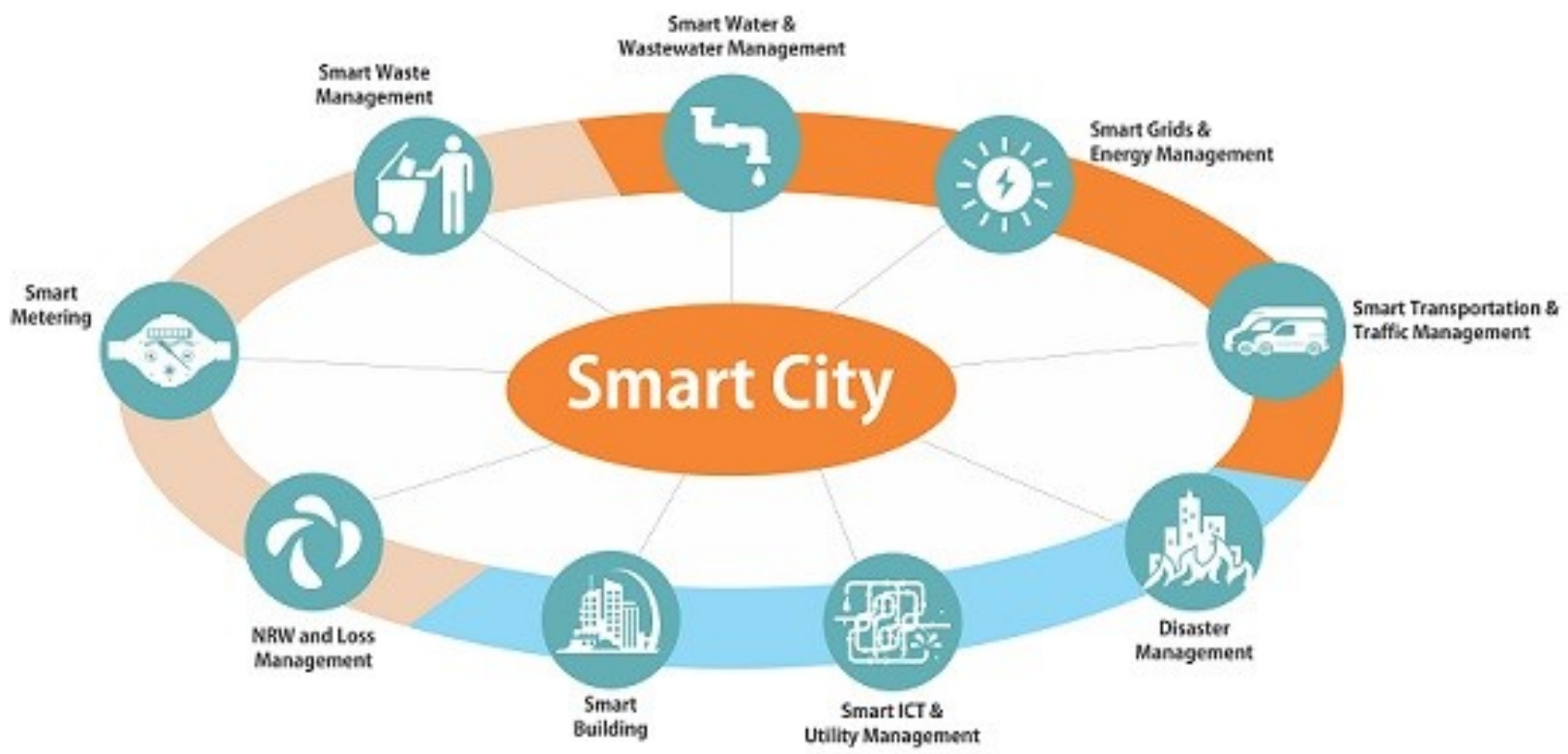

Figure 2. Main smart city services

The global market of smart cities is expected in 2020 to expense more than US $\$ 1.565$ trillion (around OMR 610.350 billion). Around 26 cities will be a smart city in 2025 which is more than $50 \%$ from Europe and North America (Amy and Susan 2015). According to Simon, Matthew,. \& Youri (2017) stated that government of U.K approximate the global market of smart city will worth around US $\$ 408$ billion in 2020. (CCSIC 2016) suggest that world experience the fourth industrial revolution due to technologies and digital development which will lead to smart infrastructure expenses worth around USI\$2.54 - 6.1 trillion. Furthermore, as per the study done by (Joshi et al. 2016) the estimation of annual spending in smart cities market will reach around US।\$16 billion (OMR 6.24 billion) by 2020. New study published by Navigant Research that the global market of smart city is anticipated to touch amount more than US $\$ 225.5$ billion (OMR 880 billion) within next decade (2020-2030).

The interested global market of smart cities is expecting to invest more than 1.565 trillion in 2020 . The management of huge investment amount is required source of money to cashflow smart cities projects. Most of smart city projects are high capital cost. There are several types of fund management or cash sources including: (Xiong 2018)

- Government Fund: usually is the main sponsors.

- Local Fund: comes from local economic development organizations.

- Community Fund: comes from community group investment companies.

- Public-Private Partnership (PPPs): cooperation of public as government with private investors to invest in community facilities, public infrastructure and other. 


\section{Journal of Student Research}

Fourth Middle East College Student Research Conference, Muscat, Sultanate of Oman

- Loan and Bond: when the fund is not available that will lead to funding by bank loans and central bank bonds.

- Private Fund: comes from private stakeholder to develop private investment in smart cities program.

Gheorghe (2015) one main component of smart city is trending for addition capacity of economic growth and globally competitive. The researcher explained some boundaries to issue smart cities such as lack in utilization of data. The financing of smart cities is better in improvement of infrastructure than innovation for servicing consumers. It is mentioned smartness degree of people depend on some specific variables such as economic weight, development of technologies and green concept. The employment of ICT in government is assisting the growth of smart cities. In addition, the researcher said there are a lot of frameworks in political, economic and culture that can influence cities to be smart. The researcher concluded the smart city as is the most recent of policies that treatment the economic depression.

There are many of standards, documentations and papers published during the ten years ago. All of it are focused in smart cities by developing technologies and infrastructures and future need of cities. In addition, most of the international standard organization are trying to collaborate together to issue standard documents for smart cities. Also, there are many conferences presented by many researchers from worldwide to discuss and study the smart cities infrastructures.

The Helix Model of Smart Cities Vision: The future of cities must need to be sustainable organizations that driving the social and economic development by putting strategic on play the role of innovation. However, smart city approach is required to operate helix model to satisfy the development of cities which serve citizen, business and community. The purpose of helix model is creating knowledge and technology to emerge the innovation of smart cities sustainable. Helix is reached to Triple, Quadruple and Quintuple. Triple Helix model is covered government, university and industry to be smart and innovation. Quadruple helix model is focusing in government, academic, citizen and industry to create future livable cities. Quintuple helix model is a system of innovation that works with 5 elements government, university, citizen, environment and industry.

\section{Government}
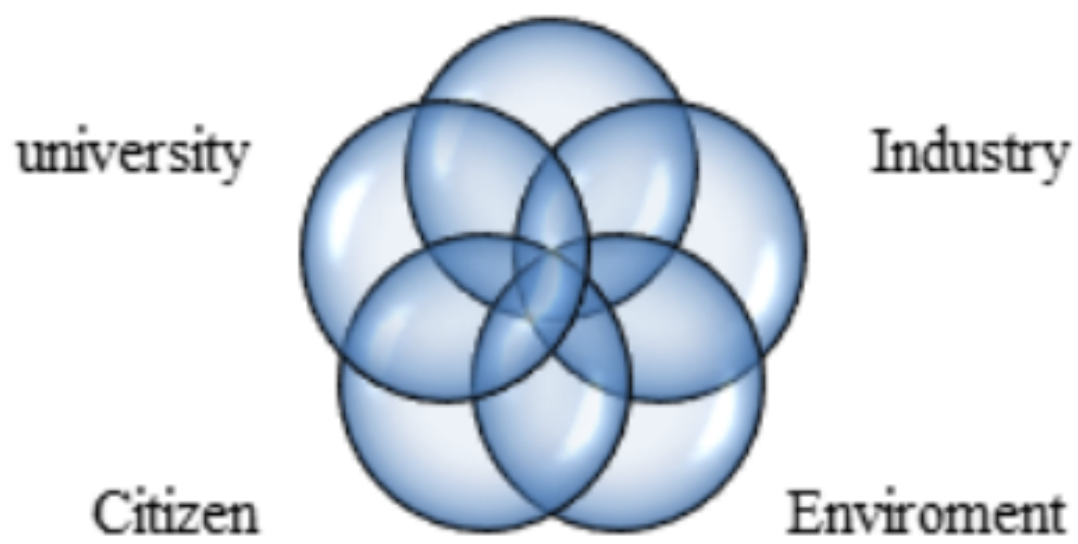

Figure 3. Quintuple helix model 


\section{Journal of Student Research}

Fourth Middle East College Student Research Conference, Muscat, Sultanate of Oman

There are critical factors that used to understand and develop smart cities. These factors including Social, technology, Sustainability, legal, Economy, Management. Each factor is playing important role in the smart city concept.

Smart cities are a group of basic elements which required to develop in smart way. Each component of smart city is covering its method and results. On other way, to implement smart people, you will get digital education, creativity, IT knowledge, excellent life management and intelligent society thinking.

In recent years, the Gulf Cooperation Countries (GCC) are leading many sustainable projects of smart cities which supported and encouraged by governments. Most of countries were started in implemented the smart city projects. There are some projects designed and in implementing progress such as Madinat Al Irfan in Muscat, Aljada Smart City Project in Al-Sharjah, Neom giga project in Tabuk, Saad Al-Abdullah City in Kuwait and other projects (Construction week online 2018).

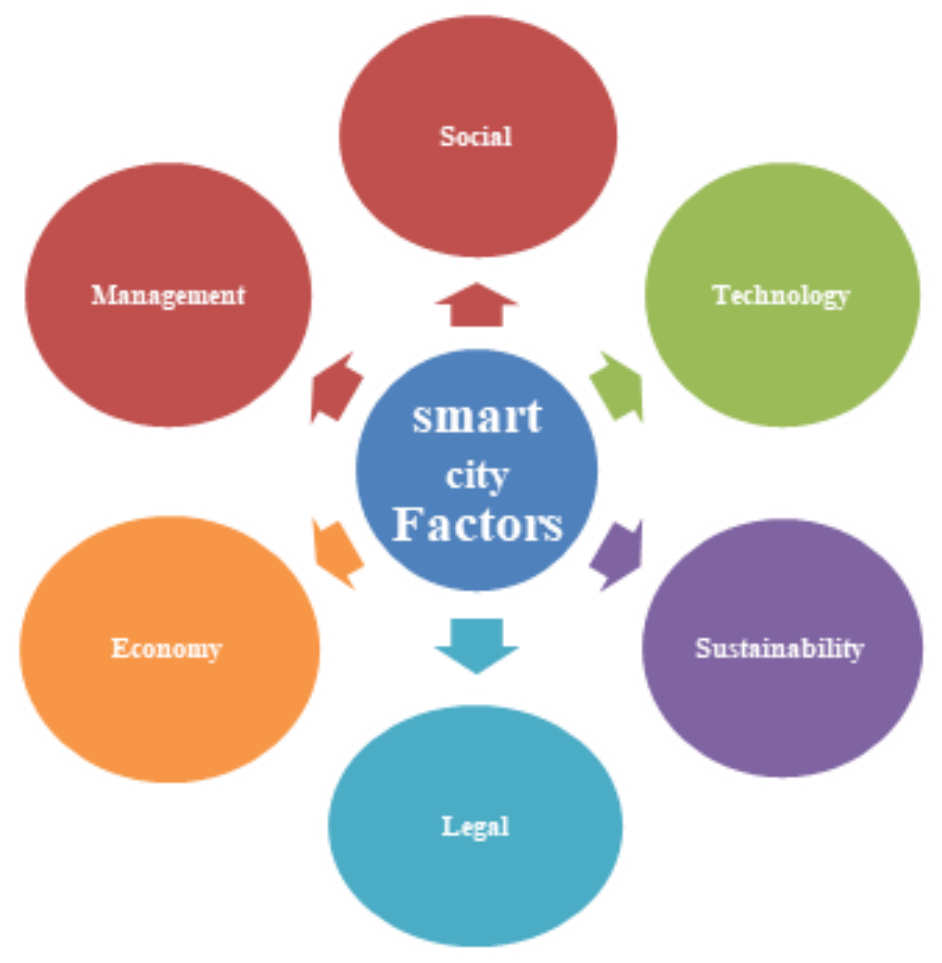

Figure 4. Key Factors of Smart city

Smart cities have become a necessary tool to develop countries. During last years, Oman started introducing the concept of smart cities. On behalf the government, the research council (TRC) started to put strategic plan that can develop cities in future by open the doors for students and researchers to focus in smart cities. In addition, TRC is presented an area to share knowledge of smart cities to public and increase the level of awareness which called Oman Smart City Platform. Oman (SCP) is the consortium of knowledge to lead smart cities initiatives. The main objectives pf the SCP is providing a space of knowledge sharing, an environment of smart city stakeholders, enable people to innovate and creative in the area of smart city through competitions and funding research. SC platform is directed by a steering committee and operate by an executive team (Smart Oman 2019).

\section{Research Methodology}


The main step in conducting the research is identifying the problem by investigating factors affecting the problem for which solutions are required. The problem in this research is focused on smart city development and the growth of technology in the world. Most of the developed countries around the world have begun to apply concepts of smart cities as compared to the cities in the Middle Eastern countries and GCC. The need to develop the infrastructure is most desirable for many people in countries with increasing the knowledge of the community. In Oman, there are a few small cities that are approaching the smart solution. Also, most citizens do not know about the smart city concepts. One of the three objectives of this research is to critically introduce a framework which will be suitable for government and private entities to start working in smart technology.

After summarizing the previous literature and studies available, the research must be designed in order to monitor the required results. The research is designed to give a full overview of details regarding the problem or theory discussed. The technical design of the research follows the mixeddesign method with a combination of both quantitative and qualitative methods to present comprehensive results. One of the most useful characteristics of mixed-design method is the possibility of triangulation. Triangulation allows to identify results with more accuracy.

The main source of data for qualitative and quantitative method is by using survey tools such as interview and questionnaires. The qualitative method enables the researcher to question key persons who are related to the smart city industry. There are four major designs for the qualitative method including Phenomenology, Ethnography, Grounded theory and Case study. Each method has different processes of implementation related to the research methodology (Prashant 2013). In this research, design used is by case study which is closer to the analysis required and the most suitable. The quantitative method enables one to evaluate the real data from the field by using different basic types including survey, correlational, experimental and causal-comparative. The Quantitative method focuses on the numerical information or data by using statistical analysis which means the collected data must be in numbers (Udemy 2014). The research is designed to apply survey or questionnaires to both public and people who work in the industry.

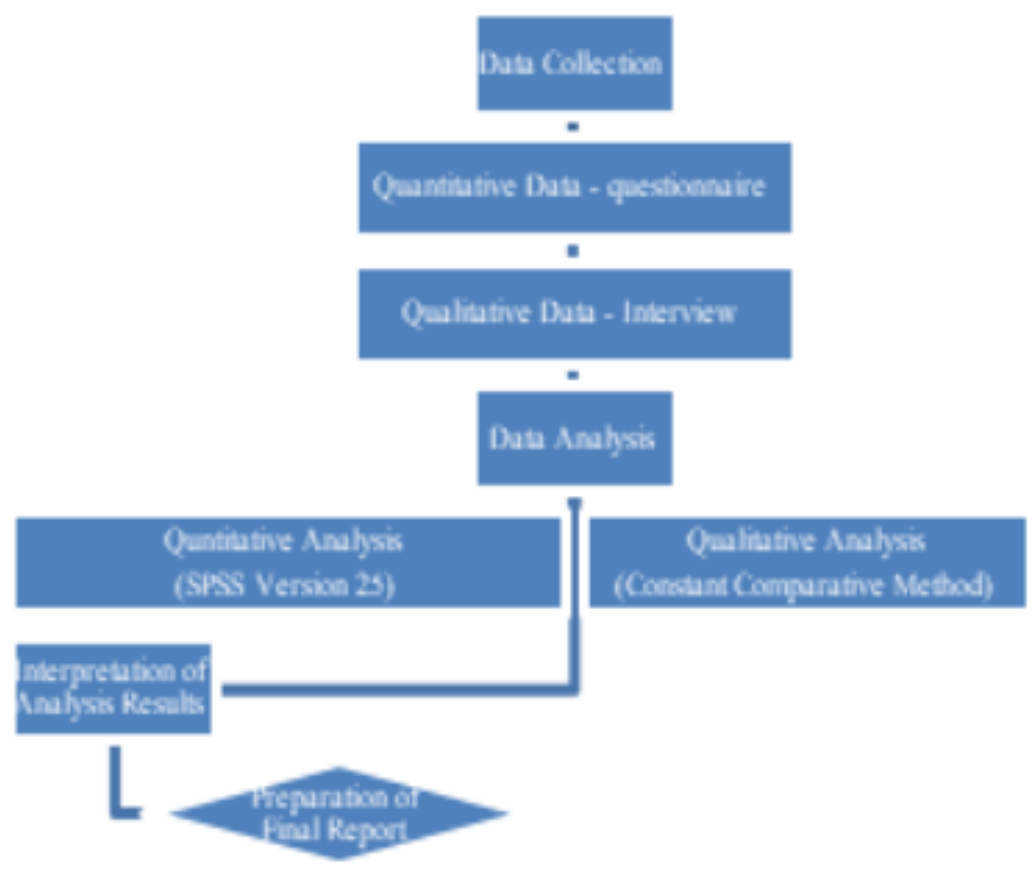

Figure 5. Research Methodology Flowchart

Data collection is the process of collecting data and information from all related resources to find and reach answers required for the research paper. It can be divided into two categories: primary 


\section{Journal of Student Research}

Fourth Middle East College Student Research Conference, Muscat, Sultanate of Oman

source of data and secondary source of data. This part is about collecting data as per the research design. It explains the way of collecting information from primary sources, which will be the qualitative method by conducting interviews with some key persons related to smart city development and the quantitative method is by giving questionnaires to include all the people, business owners, stakeholders, city development staff and other government and private employees.

There are different main cities in the Sultanate of Oman, distributed in eleven governorates namely: Muscat, Al-Rustaq, Suhar, Nizwa, Duqm, Salalah, Khasab, Sur and other. The study area is focused in Muscat city and other main cities Suhar and Nizwa. On the other hand, the areas that includes the smart city project in Oman are: Al Mouj Muscat, Madinat Al Irfan and PDO Ras Al Hamra sustainable housing project.

a lot of qualitative research has recently been criticized for being unclear about the sample size that is actually used in the research project. The reason for that is a lack of justifications in term of selecting sample size. The sample size can be justified under population numbers and other factors to decide the quantity of qualitative and quantitative sample required. However, it was recommended to use 15-30 interview sample for the case study method. The other recommendation was to use 12 or a dozen as sample of interview for qualitative method. In this research the sample selected to be not less than 6 .

In quantitative method, 385 questionnaires will be distributed for the survey as that is the sample size obtained from the formula.

As per the research guidelines and supervisor instructions for the pilot study method, the research requires distribution of questionnaires to a small number of respondents to avoid any failure during collection of data and to plan and determine if the research feasible. A pilot study was conducted for using the quantitative method before distributing to a large number of people or total sample size. However, it appears that the pilot sample size depends on many factors such as confidence level, inflation index, errors, number of the total sample required and others. Some authors recommend that the pilot trial sample size should range between 24, 30, 55 and 70 (Amy et al. 2016). For this research, it is approved to take a pilot sample size of 30 questionnaires.

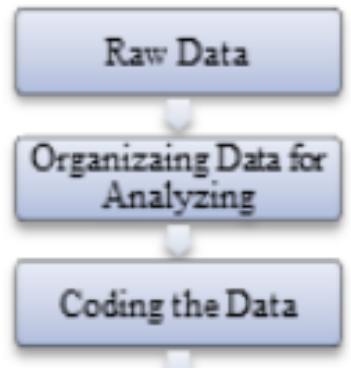

\section{Comparing incidents applicable to each category}

Integrating categories and thier properties

Delimiting the theory

Writing the theory

Figure 6. Analysis steps of Constant comparative method 


\section{Results and Discussion of the Finding}

All results from both parts in this chapter have been filtered, evaluated and analyzed to reach the research theme required. Finding of results will represent in different way to obtain ideas by tables, charts, graphs and other types.

Chart mean is obtained in 2.5 which range between agree and neutral with percentage $35 \%$ and 30 $\%$. It is explaining that most of respondents not sure if the infrastructure in Oman is ready to convert on smart city concept.

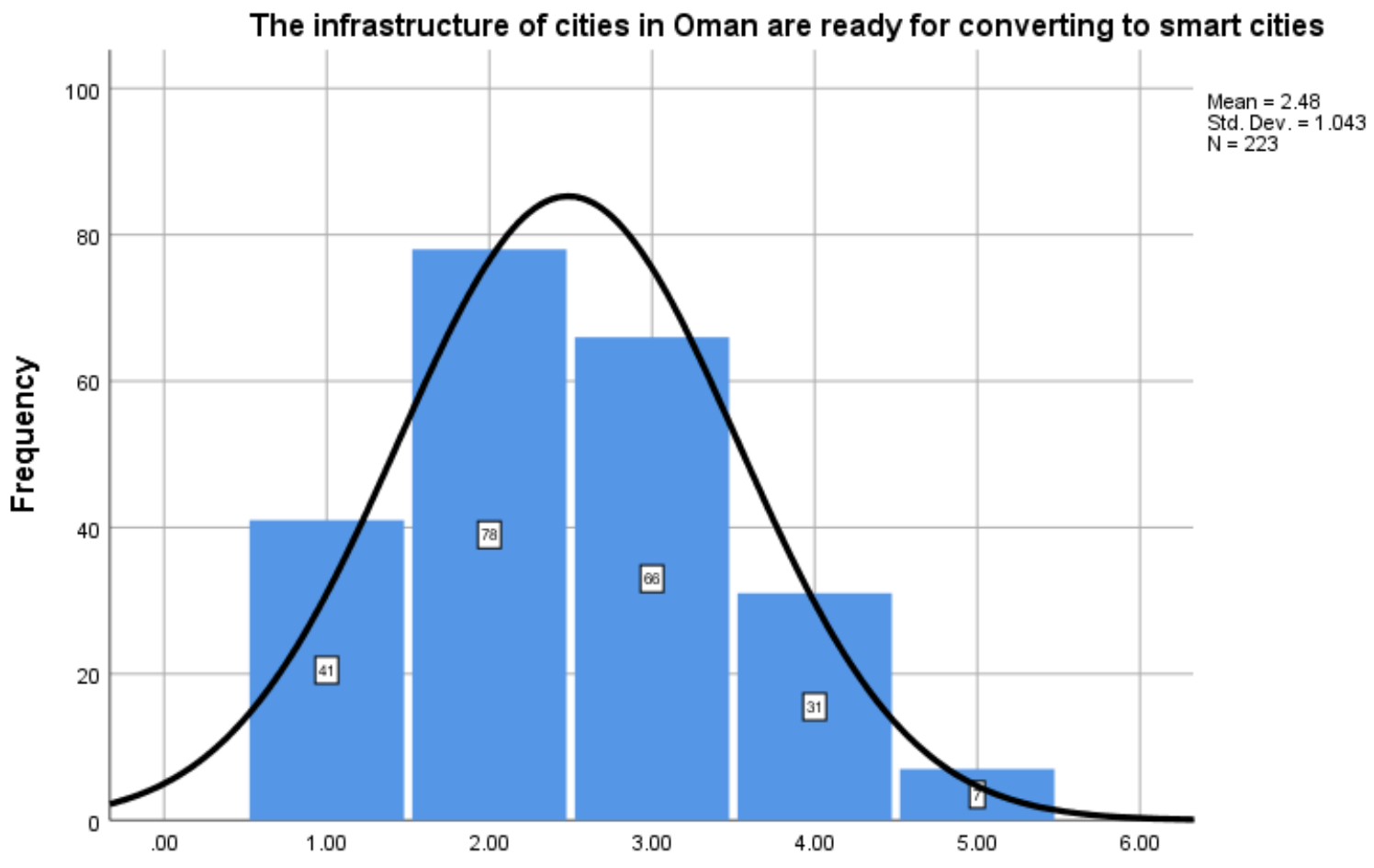

Figure 7. Readiness of the infrastructure in Oman to be smart cities

Over $81 \%$ of responses strongly agree and agree to the living in a smart city impact the community in general. Which mean the community is a main factor in smart cities development in country. It can be affecting in positive and negative way depend to the adaptions of social in the cities. Actually, the use of technology needs to use in a good way to reach the maximum level of benefits. 


\section{Journal of Student Research}

Fourth Middle East College Student Research Conference, Muscat, Sultanate of Oman

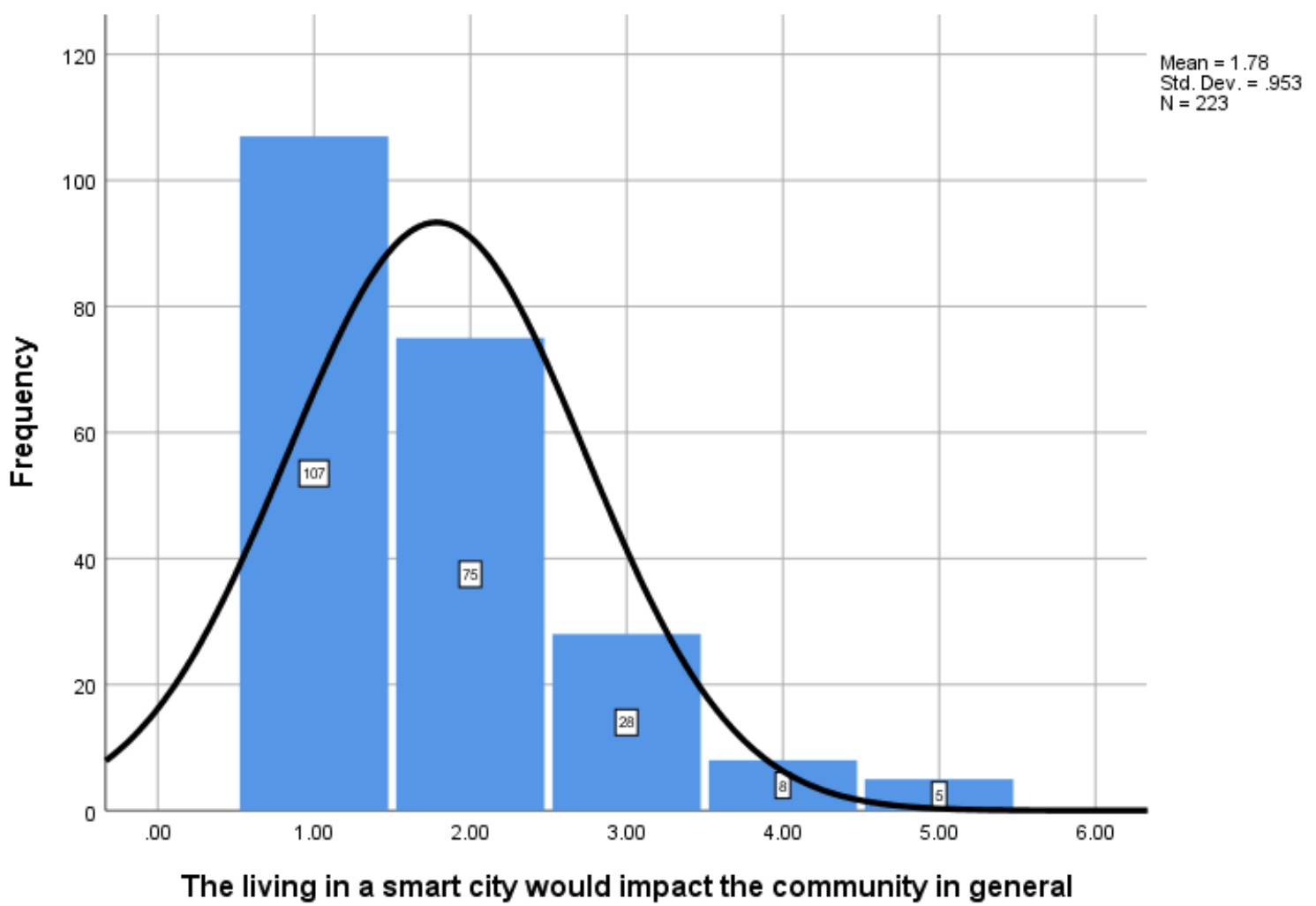

Figure 8. The general community impact of living in smart city

Over $95 \%$ of responses answered that government should start construct or develop current cities to smart concepts, which mean it is necessary from government to work and plan in smart concept to develop main cities.

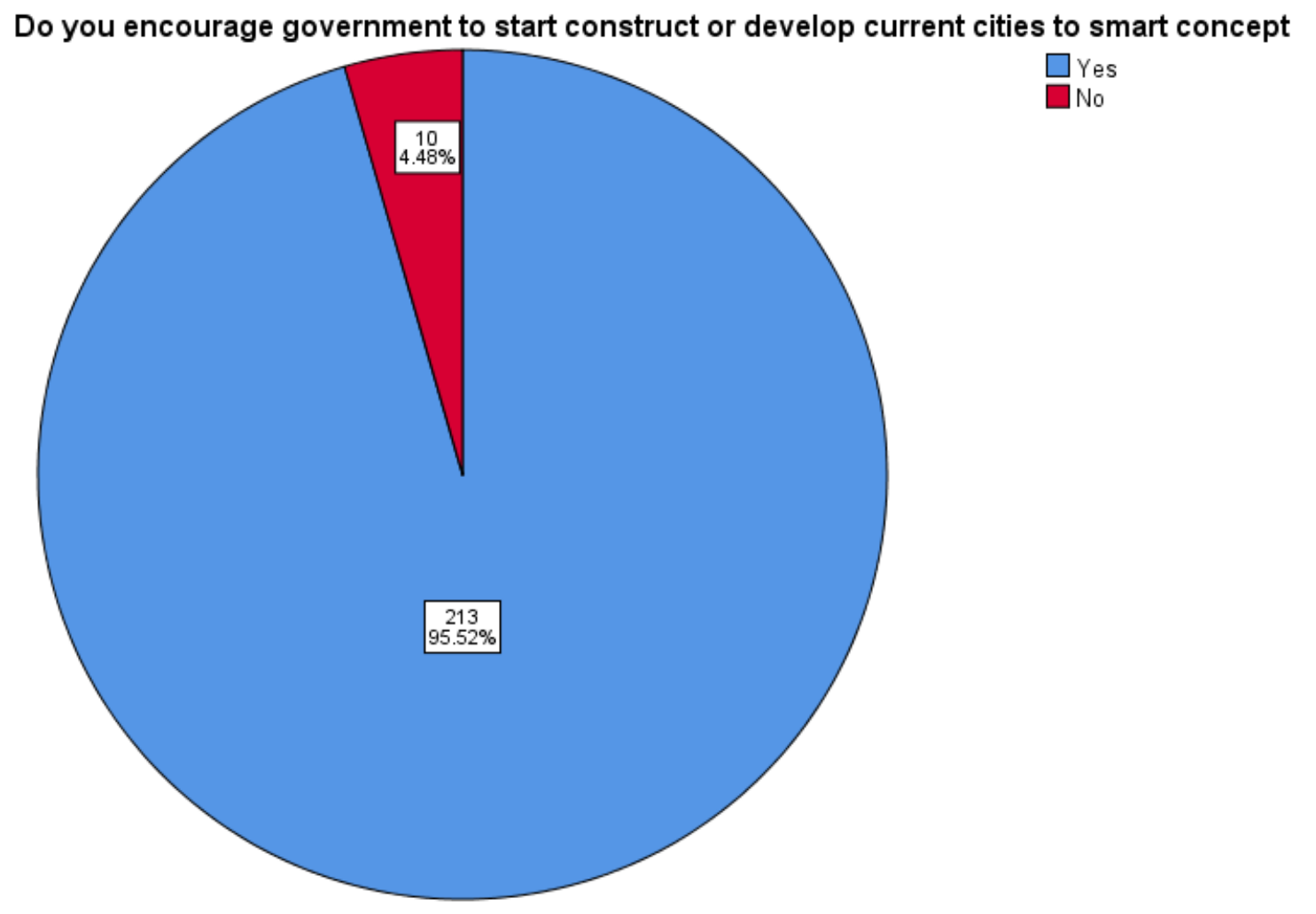


Figure 9. Participants view to construct or develop current cities to smart concept

The role of government is very imprtant to relize the smart cities by starting on development urban master paln. Over $80 \%$ of answered are encourged government to put clear view to begin implementing smart cities.

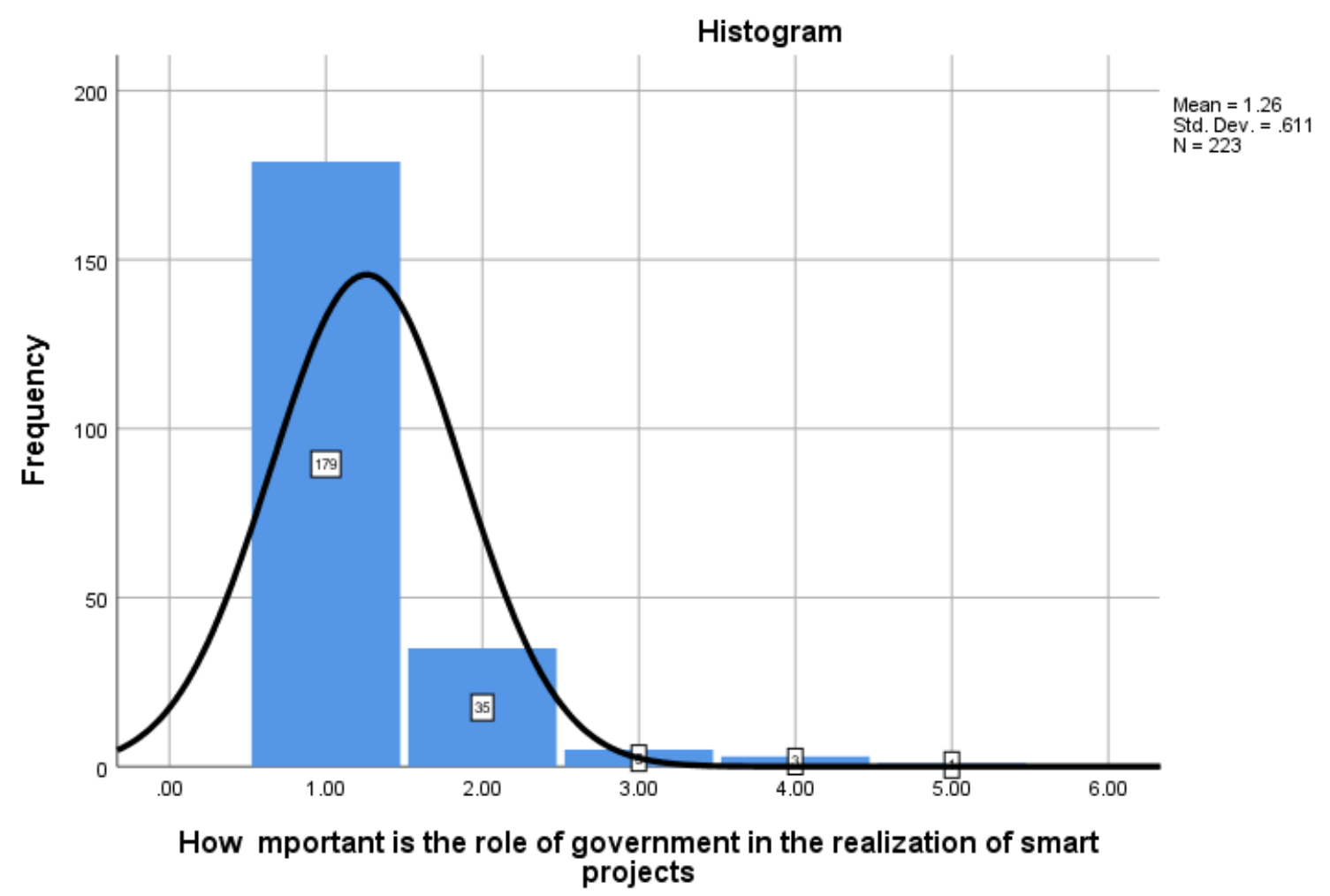

Figure 10. The role of government on Smart projects

Muscat and Duqm choose to be priority change to be smart cities in order to develop tourism, economic, transportation and services with percentage around $54 \%$ and $30 \%$.

Research results were collected through different types by qualitative and quantitative methods. The information collected was enough to get the result required. $57 \%$ from the total samples of quantitative question form collected by using electronic website. Results was giving a lot of ideas and finding that which can enhance the results of this research. The analysis of this method was done by SPSS software. On other hand, qualitative questions form through interviews with expert was valuable to confirm the research results. It was analyzed through constant comparative method. Results are strongly close in both quantitative and qualitative method.

\section{Conclusion}

There is not a specific term in Oman that to present smart city, but these cities are smart by its way. Most of results indicated that smart cities are famous and popular and required to improve the life of community. Also, it is one of many factors that develop economics locally and internationally. In order to achieve all objectives, the research focused in different objectives regarding the infrastructure of smart cities in Oman by considering economic values and social benefits. Each objective is required to give a brief conclusion that to explain the outcomes of this research.

Among the data and information received from interviews and questionnaires, it concluded that main capital cities are capable to convert in smart cities. The study received answers from 
participants to different questions that mentioned people in Oman encouraged to transfer on smart city concept and agreed that cities are ready. Which give an indicator that people in Oman feel their cities can convert to smart cities even if they do not conduct any smart project before. On other hand, interviewees mentioned to encourage government to develop cities to smart cities and they belief that main cities have good infrastructure which can lead to convert in smart cities.

The main factor to change in smart city is the impact of social life and economic development. The objective is directly tried to reach the satisfaction of people based on both social benefits and economics values. Research received many answers to the questions related to the human culture of Oman people. In addition, interviewees said that smart cities are one sources of improving quality of life to the community. They answered that smart cities are suitable and useful for people in Oman, and it can change the Omani people slightly without making any issues regards the culture and traditions.

According to the data received from quantitative interviews, it is obtained that Oman have not started any framework to implement smart cities. During meeting with experts and searching in government websites, it is difficult to find any framework of development smart cities. Most of responses are answered that they may have framework but it is used for the authority itself and confidential. In addition, there are different assessments and analysis which can presenting more details of the city status. The purpose from these assessments is gave clear framework of implementing and transferring cities to smart cities. By the way, transferring to smart cities cannot be in one day, but it needs time and should government think for long term to improve the quality of people life.

\section{The major factors that can employ for Oman vision of smart cities divided below:}
1. Smart Governance
2. Smart Economy
3. Smart Education
4. Smart Mobility
5. Smart living
6. Smart Environment

Each factor required to obtain framework by defining processes and guidelines that implement smart cities as requirements of people in Oman.

\section{Recommendations}

The new revolution of infrastructure in cities is required to match the digital development. Results appeared that new thinking of enhancing cities is by keeping cities smart. It is required to exploit data and information received to present better cities. Big data and smart cities can be the powerful to realize the requirements of cities. The following are some recommendations and suggestions found through this research:

- Encourage a culture of innovation

- Support different kinds of cross-system initiatives

- Support linkage between different initiatives

- Running effective sources of financing on future cities laboratory 


\section{Journal of Student Research}

Fourth Middle East College Student Research Conference, Muscat, Sultanate of Oman

- Collaborative between political and professional public agency leaders

- Collaborate academic experts on helping smart cities initiatives

- Cooperation with stakeholder leaderships to develop smart cities such as private investors, lead investors and funders

- Create and attract local and global investment on smart cities

- Taking advantages of infrastructure projects to transfer services

- Using the local own resources to catalyze changes

- Building a collaborative relationship with citizen to provide useful information required

- Increasing the use of BIM software

- Developing the smart city standards

- Instrumented cities by deploying sensors, CCTV and other devices that can collect data to solve any issues

- Using and opening of data in a purpose that concern to privacy and security

- Using of analytics and decision-making systems

- Enhancing studies and researches on smart cities into responsive cities concept

- Designing cities to be sustainable

- Designing cities to be green as open space areas required

- Bring ideas and experiences used in smart cities and apply them in the major cities of Oman

\section{References}

About Oman (2019) smart city and industry [online] available from

<http://smartcityoman.com/en/about-oman/> [14 April 2019]

Hongbo, S., Sang, B.T., Xiaowei, L., and Tianyi, Z. (2018) 'How to Evaluate Smart Cities

Construction? A Comparison of Chinese Smart City Evaluation Methods Based on PSF'. Molecular

Diversity Preservation International [online] 10 (1), 37 available from <https://doi.org/10.3390/

su10010037> [26 June 2019]

UKEssays (2013) The History of Smart Cities Concept Information Technology Essay [online] available from <https://www.uniassignment.com/essay-samples/information-technology/the-historyof-smart-cities-concept-information-technology-essay.php?vref=1 > [24 June 2019]

Keta, M. (2015) 'Smart city, Smart Administration and Sustainable Development'. Romanian Economic and Business Review 10 (3), 43-56

Debra, L., and John, W.G. (2018) "Small and Smart: Why and How Smart City Solutions Can and Should be Adapted to the Unique Needs of Smaller Cities". DE GRUYTER 12 (1), 21-36 


\section{Journal of Student Research}

Fourth Middle East College Student Research Conference, Muscat, Sultanate of Oman

Architexturez (2015) How LA Used Big Data to Build a Smart City in the 1970s [online] available from <https://architexturez.net/pst/az-cf-169297-1435054977> [24 June 2019]

Alawdah, A. (2017) “An Exploratory Study of Smart City Initiatives: Theory, Practice, and Linkage to Sustainability". Doctor of Management in information Technology. Lawrence Technological University

Sik, K.L. (2016) 'Smart city'. Master of Science. State university of New York

Ignasi, C., and Matías I.Z. (2015) 'Smart city or smart citizens? The Barcelona case'. Journal of Strategy and Management 8 (3), 266-282

Sajid, K., Mina, W., Kichan, N., and Prakash, K.C. (2017) 'Smart City and Smart Tourism: A Case of Dubai'. Molecular Diversity Preservation International

Ayşen, C. (2018) "Smart Cities and Smart Tourism: Smart City Projects and Applications in Turkey". Multidisciplinary Academic Conference

Debra, L., and John, W.G. (2018) "Small and Smart: Why and How Smart City Solutions Can and Should be Adapted to the Unique Needs of Smaller Cities". DE GRUYTER 12 (1), 21-36

Jalali, R. (2017) 'Community-Oriented Architecture for Smart Cities'. Doctor of Philosophy in Computer Science. University of Ontario Institute of Technology

Radovan, N., Radek, K., and Jaroslav, K. (2014) 'Smart City Concept, Applications and Services'. Journal of Telecommunications System \& Management [online] 3 (2), 1-8 available from $<$ https://www.omicsonline.org/ open-access/smart-city-concept-applications-andservices-2167-0919-117.php?aid=33684 > [20 June 2019]

Ramboll (2019) Smart city concepts and technologies [online] available from <https://ramboll.com/s ervices-and-sectors/planning-and-urban-design/smart-city-concepts-and-technologies> [20 June 2019]

Aaron Hesse (2017) What is the concept of a smart city? [online] available from < https://www.quora.com/What-is-the-concept-of-a-smart-city> [22 June 2019]

Simon, J., Matthew, C., \& Youri, D. (2017) 'Smart Cities: Towards a New Citizenship Regime? A Discourse Analysis of the British Smart City Standard'. Journal of Urban Technology [online] 24 (4), 29-49 available from < https://doi.org/10.1080/10630732.2017.1336027> [25 June 2019]

Cambridge Centre for Smart Infrastructure and Construction (2016) Smart Infrastructure: Getting More from Strategic Assets [online] available from <http://www-smartinfrastructure.eng. cam.ac.uk/files/the-smart-infrastructure-paper> [30 June 2019]

Joshi, S., Saxena, S., Godbole, T., and Shreya (2016) 'Developing Smart Cities: An Integrated Framework'. 6th International Conference on Advances on Computing \& Communications [online] 6 (8), 902-909 available from < www.sciencedirect.com> [26 June 2019]

Xiong, X. (2018) 'cost-benefit analysis of smart cities technologies and applications'. Master of Civil Engineering. University of Delaware

Gheorghe, H. (2015) 'The Economic Value of Smart City Technology'. Economics, Management, and Financial Markets 10 (4), 76-82

Construction week online (2018) The GCC's top smart city projects of 2018 [online] available from 


\section{Journal of Student Research}

Fourth Middle East College Student Research Conference, Muscat, Sultanate of Oman

<https://www.constructionweekonline.com/article-50760-the-gccs-top-smart-city-projects-of-2018> [10 July 2019]

Smart Oman (2019) smart city platform [online] available from <http://en.smartoman.om/ AboutSmartCityPlatform .aspx?cms=iQRpheuphYtJ6pyXUGiNqkP7woZPUrlc > [10 July 2019]

Sina Safinia, Zamarad Al-Hinai, Hussin AM Yahia, Mohammed FM Abushammala, 2017. Sustainable construction in sultanate of Oman: factors effecting materials utilization. Procedia engineering.196. Page 980-987

Prashant, K.A. (2013) 'QUALITATIVE RESEARCH DESIGNS: A CONCEPTUAL FRAMEWOR'.

International Journal of Social Science \& Interdisciplinary Research [online] 2(1), 118-124 available from < indianresearchjournals.com > [15 July 2019]

Udemy (2014) Types of Quantitative Research for Students and Researchers [online] available from <https://blog.udemy.com/types-of-quantitative-research/> [15 July 2019] 